\title{
Longitudinal Effects of Excessive Smartphone Use on Stress and Loneliness: The Moderating Role of Self-Disclosure
}

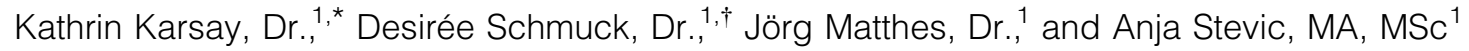

\begin{abstract}
The present study investigates how excessive smartphone use predicts users' stress and loneliness while taking the moderating role of online self-disclosure into account. We conducted a two-wave panel survey with a quota sample of smartphone users $(n=461$ at time 2 [T2]). We found no direct effects of excessive smartphone use on stress or loneliness. However, our results showed that online self-disclosure moderates the postulated relationships. That is, excessive smartphone use (time 1 [T1]) predicts increased stress (T2), for those smartphone users who do engage in little online self-disclosure. However, for those who communicate their feelings, anxieties, and problems online, excessive smartphone use (T1) can even reduce loneliness (T2) and relieve stress (T2).
\end{abstract}

Keywords: smartphone use, excessive use, stress, loneliness, self-disclosure

\section{Introduction}

W ITH ITS MANIFOLD USES the smartphone has become an integral technology in our everyday lives. Many applications of the smartphone are for stress relief and for social purposes; excessive smartphone use may be accompanied by several negative consequences, including stress and loneliness. ${ }^{1}$ Thus far, numerous studies have addressed the antecedents and effects of excessive Internet and social networking site (SNS) use, but considerably less research has been conducted on excessive smartphone use. ${ }^{1}$ The ability to access the internet and SNSs with a smartphone at all hours and locations renders excessive use especially facile. ${ }^{2-4}$ Thus, excessive smartphone use bears further study, and there are several research gaps that can be identified.

First, individual predispositions and underlying usage motives make some people more susceptible to media effects than others. ${ }^{5}$ However, the majority of earlier research on excessive Internet or smartphone use has not considered such potential moderators. Thus, we introduce online self-disclosure as a key moderator in this line of research. Studies showing that online self-disclosure has several benefits for relationships and mental health $^{6-8}$ suggest that intensive smartphone use may not always result in negative consequences, but rather depend on the extent users engage in online self-disclosure.

Second, studies on excessive use predominantly relied on convenience samples, mostly university students, ${ }^{9-15}$ and only very few researchers have investigated a representative or quota-based sample. ${ }^{4,16}$ However, as smartphone use is not limited to young adults, including a broad age range of users is important. For example, in Germany, where the study has been conducted, $78 \%$ of citizens own a smartphone. ${ }^{17}$ Moreover, adults also increasingly use the smartphone to connect to friends, family, or colleagues on SNSs. ${ }^{18}$ Finally, the large majority of studies are cross-sectional, which do not allow causal or temporal inferences of the proposed relations. Thus, longitudinal research investigating the consequences of excessive smartphone use is needed.

The present study addresses these research gaps by investigating the consequences of excessive smartphone use for stress and loneliness while taking the moderating role of selfdisclosure into account. To this end, we conducted a twowave panel survey with a quota-based sample of smartphone users.

\section{Excessive smartphone use and stress}

We define excessive smartphone use as overly high cognitive, emotional, and behavioral involvement with the smartphone. ${ }^{4}$ According to Lee et al. ${ }^{15}$ such use subsumes addictivelike symptoms and signs of deficient self-regulation. Researchers also referred to this type of use as compulsive, ${ }^{15}$ maladaptive, ${ }^{9}$ and problematic ${ }^{19}$ or used the term smartphone addiction. ${ }^{20}$ Although these concepts often share a conceptual

${ }^{1}$ Department of Communication, University of Vienna, Vienna, Austria.

* Current address: School for Mass Communication Research, Faculty of Social Sciences, KU Leuven, Leuven, Belgium.

${ }^{\dagger}$ Current address: Department of Media and Communication. LMU Munich, Munich, Germany. 
overlap and are sometimes used interchangeably, we prefer the term excessive use. Following early academic discussions on Internet use, we argue that while overuse of smartphones might have negative consequences for individuals, it is not necessarily pathological in terms of a clinical disorder or genuine addiction. $^{19}$

Previous studies suggest a bidirectional relation between excessive smartphone use and stress. High distress compels people to use social media to disclose sensitive and negative emotions. $^{21}$ Specifically, emotional stress ${ }^{22}$ and social stress have been found to predict addictive smartphone behavior among adults ${ }^{23}$ as well as among adolescents. ${ }^{24}$ Although the relation between smartphone use and stress might be reciprocal, especially the perception of using one's smartphone excessively might be a deciding factor in increasing user's stress. ${ }^{15}$

Given that the smartphone has become an integral part of the daily life, not being able to use the phone might result in negative feelings, such as stress, irritation, and feelings of disconnectedness. ${ }^{3}$ Being constantly available and connected to others, might also evoke technostress (i.e., stress related to new technologies) ${ }^{15}$ or psychological distress. ${ }^{3,9}$ Researchers have repeatedly found correlational evidence for a positive association between excessive smartphone use and stress among children ${ }^{25}$ and young adults. ${ }^{26,27}$ However, existing research lacks an investigation of smartphone users of several age segments in a longitudinal context. Based on the theoretical framework and prior correlational evidence, we postulated the following hypothesis:

\section{H1: Excessive smartphone use predicts higher stress over time.}

\section{Excessive smartphone use and loneliness}

Despite the manifold communicative uses of the smartphone, researchers have voiced concerns with regard to the potential of mobile phone use in fostering loneliness. As proposed in the so-called displacement hypothesis, early studies suggest that using online or digital media, substitutes for time spent on face-to-face interaction in an offline setting. ${ }^{28}$ It is further assumed that online relationships are rather superficial and users do not experience the closeness which is typically received from strong-tie relationships. ${ }^{29}$ Recently, researchers have also pointed to the new phenomenon of phubbing that refers to the act of paying attention to one's phone instead of talking to the person in one's company. ${ }^{30}$

However, scholars have also argued for the stimulation hypothesis, which states that time spent online with existing friends might increase the quality of these friendships and therefore decrease loneliness. ${ }^{29}$ With regard to the bidirectional relationship between excessive use and loneliness, the existing literature provides slightly more support for the displacement hypothesis than for the stimulation hypothesis.

Findings from correlational studies showed a positive association between excessive smartphone use and loneliness. ${ }^{10,31-33}$ Although the only longitudinal study thus far found no evidence for an increase of loneliness, ${ }^{34}$ the author argued that excessive use leads users to put less effort to build meaningful relationships, which might ultimately increase loneliness. ${ }^{34}$ Moreover, a recent longitudinal study found that heavy Facebook use resulted in higher loneliness, while low to moderate levels of Facebook use even decreased loneliness. ${ }^{35} \mathrm{We}$ assumed that using the smartphone excessively might have detrimental consequences for (faceto-face) communication with close ties and therefore increase loneliness. Accordingly, we hypothesized:

\section{H2: Excessive smartphone use predicts higher loneliness over time.}

\section{The moderating role of online self-disclosure}

Self-disclosure refers to the act of revealing personal and intimate information about oneself to others. ${ }^{36}$ Self-disclosure plays a key role in developing closeness with family, friends, and romantic partners-in offline contexts as well as in online environments. $^{36,37}$ Sharing personal information online has been associated with a number of benefits for relationships and mental health. ${ }^{6-8}$

For instance, online self-disclosure has been found to buffer stress by moderating the relation between stressful life events and life satisfaction. ${ }^{38}$ Individuals experienced fewer depressive symptoms and heightened life satisfaction when engaging in online self-disclosure during stressful periods. Further analyses showed that online self-disclosure mobilized social support, which helped individuals deal with their stressful situations in life. ${ }^{38}$ Similarly, seeking online support on Facebook reduced the effect of adolescents' daily stress on depressed mood. ${ }^{39}$ However, choosing not to share important life events online increased individuals' levels of stress. ${ }^{40}$

With regard to loneliness, Shaw and Gant ${ }^{41}$ showed that chatting anonymously on the Internet, for a period of 4-8 weeks, significantly decreased loneliness, while participants' perceptions of social support increased. Likewise, using the Internet and SNSs for communicative purposes, has been positively related to decreased loneliness, positive affect, wellbeing, and social support. ${ }^{42-44}$ Findings from a longitudinal study with adolescents showed that instant messaging had a positive effect on the quality of existing friendships, ${ }^{45}$ which could be entirely explained by adolescents' tendency to disclose intimate information online. ${ }^{45}$

These findings suggest that sharing personal experiences and feelings online might help maintain closeness to friends and family and therefore reduce stress and loneliness. Thus, excessive smartphone use may not always result in negative consequences, but rather depend on whether users engage in self-disclosure. However, systematic research examining this postulated relationship is still missing. Accordingly, we investigated the moderating role of online self-disclosure, which might explain existing conflicting findings regarding excessive smartphone use, stress, and loneliness. Specifically, we assumed:

\section{H3: Self-disclosure reduces the influence of excessive} smartphone use on (a) stress and (b) loneliness over time.

\section{Materials and Methods \\ Sampling and procedure}

We conducted an online two-wave panel survey with a quota sampling procedure for smartphone users with regard to age, gender, and education in Germany. Participants were recruited through a private research institute. Data were 


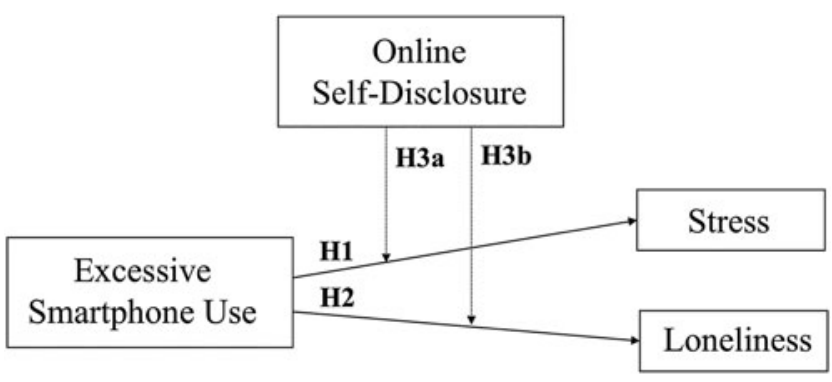

FIG. 1. Theoretical model.

collected with a 4-month interval at two time points between March/April 2018 (time 1 [T1]) and July/August 2018 (time 2 [T2]). The response rate at T1 was $\sim 4 \%$ and at T2 $65 \%$.

Participants were invited to take part in an online survey questionnaire. Only those respondents who provided their consent and were 16 years old or older could participate. In the first wave, 833 individuals participated (T1: $54.1 \%$ women, $M_{\text {age }}=45.44, S D=14.83$, range: $16-65$ years) and in the second wave, 461 individuals participated (T2: 53\% women, $M_{\text {age }}=48.65, S D=13.02$, range: $18-65$ years). The attrition rate was $45 \%$. Men as well as 16-29-year-old participants and 30-39-year-old participants were slightly underrepresented in our analytical sample due to the attrition rate $(n$ at $\mathrm{T} 2=461)$.

Participants who dropped out at T2 scored higher in excessive use at T1, $F(1,800)=12.73, p=0.000, \eta^{2}=0.01$, had higher stress levels at T1, $F(1,831)=19.51, p=0.000$, $\eta^{2}=0.02$, and had higher self-disclosure levels at T1 $F(1$, $831)=9.26, p=0.002, \eta^{2}=0.01$, compared with respondents who participated in both waves. Loneliness did not differ between individuals who dropped out compared with those who did not drop out, $F(1,824)=3.49, p=0.062, \eta^{2}=0.00$.

The current paper uses data that is part of a larger study project that examines the links between smartphone use and well-being. More information about the study project can be obtained from the first author.

\section{Measures}

The Appendix displays all items. We measured excessive use with three items from the smartphone involvement scale ${ }^{46}$ and four items from the deficient Internet self-regulation scale $^{47}$ (adapted to the context of smartphones). A principal component analysis indicated a one-dimensional scale (eigenvalue $=4.25$; accounting for $60.74 \%$ of the variance; $\alpha=0.87)$. Furthermore, we assessed online self-disclosure with three items $(\alpha=0.93)$ based on Schouten et al. ${ }^{48} \mathrm{We}$ measured stress with the Brief Inventory of Perceived Stress $\operatorname{scale}^{49}$ (T1: $\alpha=0.88$; T2: $\alpha=0.91$ ). Lastly, we assessed loneliness with four items of the UCLA Loneliness scale ${ }^{50}$ (T1: $\alpha=0.89 ; \mathrm{T} 2: \alpha=0.89$ ).

\section{Data analysis}

We conducted separate linear regression analyses using the lavaan ${ }^{51}$ package in $\mathrm{R}$. We entered manifest variables and controlled for gender, age, educational level (dummy-coded: below high school degree vs. high school degree or higher), and autoregressive effects (e.g., stress at T1 as a predictor of stress at T2). Figure 1 visualizes the theoretical model. Table 1 displays the descriptive statistics and the zero-order correlations between all variables in the model.

\section{Results}

\section{Testing the hypothesized model}

In H1, we assumed that excessive smartphone use at T1 predicts higher levels of stress at T2. Table 2 and Figure 2 display all results. The results did not support our hypothesis, as we found no direct association of excessive smartphone use on stress $(b=0.04, S E=0.05, p=0.038)$. Although there was a trend to statistical significance, our results did not achieve the conventional threshold of significance and we found no positive association between excessive smartphone use at T1 and loneliness at T2 $(b=0.03, S E=0.05$, $p=0.054$ ) as expected in $\mathrm{H} 2$.

Furthermore, the analysis showed a significant interaction effect of excessive smartphone use and online self-disclosure on stress $(b=-0.19, S E=0.04, p<0.001)$. We plotted the significant interaction with the Johnson-Neyman technique ${ }^{52}$ (Fig. 3). The figure shows that excessive smartphone use predicted stress when online self-disclosure was low (below 1.32 on a 5-point scale), but reduced stress when online selfdisclosure was high (above 2.51 on a 5-point scale). Thus, $\mathrm{H} 3 \mathrm{a}$ was confirmed. We also found a significant interaction effect of excessive smartphone use and online selfdisclosure on loneliness $(b=-0.13, S E=0.04, p<0.01)$. The Johnson-Neyman plot (Fig. 4) shows that excessive smartphone use reduces loneliness, when online selfdisclosure is high (above 2.96 on a 5-point scale), which confirms $\mathrm{H} 3 \mathrm{~b}$.

\section{Discussion}

Studying the implications of smartphone use on individuals' wellbeing is of central importance-in particular, if the smartphone is used excessively. ${ }^{1}$ Using data from a

Table 1. Descriptive Statistics and Zero-Order Correlations

\begin{tabular}{llcccccccc}
\hline & Min & Max & M (SD) & 1 & 2 & 3 & 4 & 5 \\
\hline 1 & Excessive smartphone use (T1) & 1 & 5 & $2.44(0.87)$ & 1 & & & & \\
2 & Online self-disclosure (T1) & 1 & 5 & $1.84(0.94)$ & $0.476^{* *}$ & 1 & & & \\
3 & Stress (T1) & 1 & 6 & $2.52(0.98)$ & $0.390^{* *}$ & $0.281^{* *}$ & 1 & \\
4 & Stress (T2) & 1 & 6 & $2.49(1.06)$ & $0.283^{* *}$ & $0.270^{* *}$ & $0.618^{* *}$ & 1 & \\
5 & Loneliness (T1) & 1 & 5 & $2.49(1.04)$ & $0.236^{* *}$ & $0.217 * *$ & $0.527^{* *}$ & $0.393^{* *}$ & 1 \\
6 & Loneliness (T2) & 1 & 5 & $2.47(1.04)$ & $0.191^{* *}$ & $0.214^{* *}$ & $0.409^{* *}$ & $0.556^{* *}$ & $0.612^{* *}$ \\
\hline
\end{tabular}

$n=461, * * p<0.01$.

$M$, mean; $S D$, standard deviation; T1, time 1; T2, time 2. 
Table 2. Predictors of Stress and Loneliness (Unstandardized Coefficients)

\begin{tabular}{|c|c|c|c|c|}
\hline & \multicolumn{2}{|c|}{ Stress (T2) } & \multicolumn{2}{|c|}{ Loneliness (T2) } \\
\hline & $\begin{array}{l}\text { Model (1) } \\
\text { b (SE) }\end{array}$ & $\begin{array}{l}\text { Model (2) } \\
\text { b (SE) }\end{array}$ & $\begin{array}{l}\text { Model (3) } \\
\text { b (SE) }\end{array}$ & $\begin{array}{l}\text { Model (4) } \\
\text { b (SE) }\end{array}$ \\
\hline Constant & $1.27 * * *(0.27)$ & $0.06(0.35)$ & $1.26 * * *(0.26)$ & $0.47(0.35)$ \\
\hline Gender (T1) & $-0.21 * *(0.08)$ & $-0.22 * *(0.08)$ & $-0.05(0.08)$ & $-0.06(0.08)$ \\
\hline Age (T1) & $-0.004(0.003)$ & $-0.001(0.003)$ & $-0.01(0.003)$ & $-0.004(0.003)$ \\
\hline $\begin{array}{l}\text { Excessive smartphone use } \\
\text { (T1) }\end{array}$ & $0.04(0.05)$ & $0.37 * * *(0.10)$ & $0.03(0.05)$ & $0.26 * *(0.10)$ \\
\hline Stress (T1) & $0.64 * * *(0.05)$ & $0.65 * * *(0.04)$ & & \\
\hline Loneliness (T1) & & & $0.61 * * *(0.04)$ & $0.61 * * *(0.04)$ \\
\hline Online self-disclosure (T1) & & $0.66 * * *(0.12)$ & & $0.43 * * *(0.12)$ \\
\hline $\begin{array}{l}\text { Excessive smartphone use } \\
\text { (T1) } \times \text { online self- } \\
\text { disclosure (T1) }\end{array}$ & & $-0.19 * * *(0.04)$ & & $-0.13 * *(0.04)$ \\
\hline Observations & 440 & 440 & 440 & 440 \\
\hline$R^{2}$ & 0.40 & 0.44 & 0.39 & 0.41 \\
\hline Adjusted $R^{2}$ & 0.39 & 0.43 & 0.39 & 0.40 \\
\hline Residual SE & $0.84(d f=435)$ & $0.81(d f=433)$ & $0.83(d f=435)$ & $0.82(d f=433)$ \\
\hline$F$ statistic & $71.19 * * *(d f=4 ; 435)$ & $55.61 * * *(d f=6 ; 433)$ & $69.84 * * *(d f=4 ; 435)$ & $49.87 * * *(d f=6 ; 433)$ \\
\hline
\end{tabular}

longitudinal two-way panel survey with a quota sample of smartphone users in Germany, we aimed to test the negative relations of excessive smartphone use with stress and loneliness as well as the moderating role of online self-disclosure in these associations.

In contrast to previous studies, ${ }^{12}$ we found no direct association of excessive smartphone use with loneliness and stress. For instance, Kim et al. ${ }^{53}$ found that loneliness was both a predictor and a consequence of unregulated Internet use suggesting the vicious cycle of problematic online use. Similarly, researchers have shown that compulsive Internet use predicted higher levels of loneliness among adolescents. ${ }^{54}$ However, in particular previously found associations of problematic mobile phone use with stress reveal only small effect sizes. ${ }^{55}$

Our longitudinal study suggests, for the first time, that these small effects might be rather short-lived and diminish over time. Moreover, our findings show that excessive smartphone use does not automatically increase stress and loneliness. Instead, the type of smartphone use determines these relations. Thus, it is not the quantity, but the quality of smartphone use that matters.

On the one hand, for those who did not communicate their feelings and problems, that is, did not engage in selfdisclosure, excessive smartphone use predicted increased

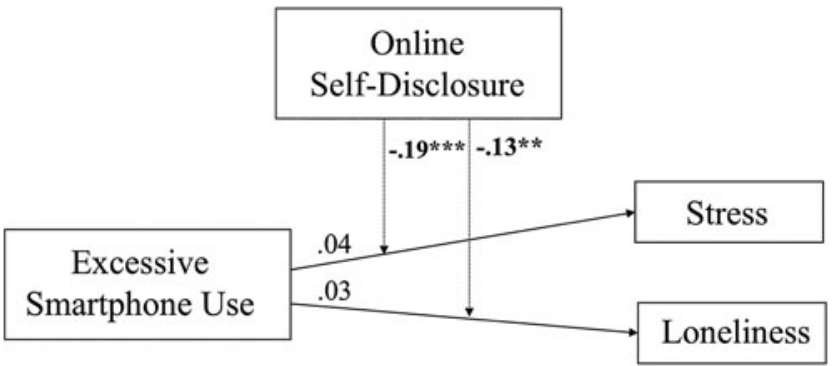

FIG. 2. Hypothesized effects. Values represent unstandardized coefficients; $* * * p<0.001 ; * * p<0.01$. levels of stress (but not loneliness) 4 months later. This finding corroborates earlier research showing that not sharing important life events online increased stress. ${ }^{40} \mathrm{~A}$ further explanation could be that those who use the smartphone excessively but largely refrain from online self-disclosure, might generally use the smartphone to a greater extent for noncommunicative purposes (e.g., passively following other people's profiles). Noncommunicative SNS use has been repeatedly associated with negative outcomes, such as social comparison, depressive symptoms, and decreased wellbeing. ${ }^{56-58}$

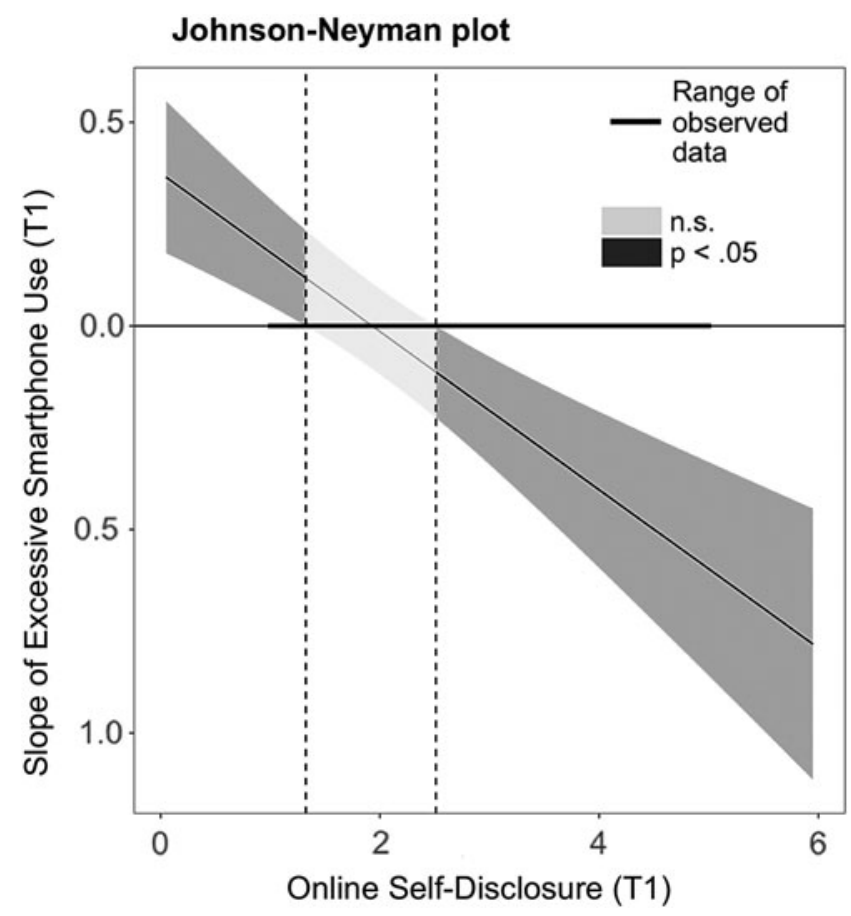

FIG. 3. Johnson-Neyman plot for the interaction of excessive smartphone use and online self-disclosure on stress. 


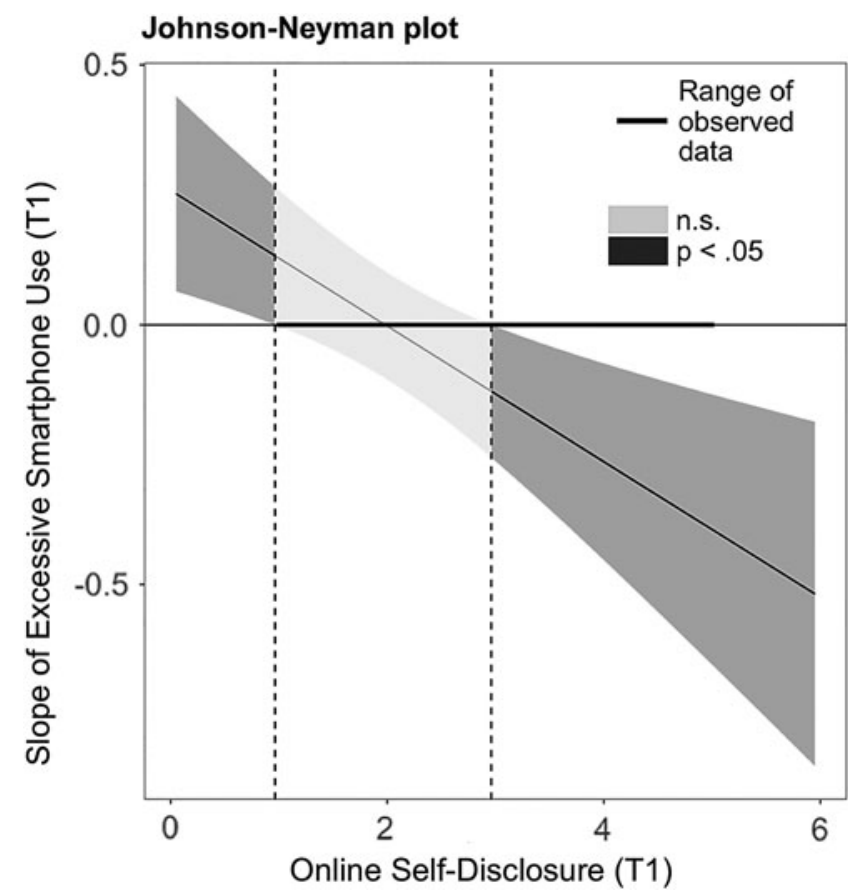

FIG. 4. Johnson-Neyman plot for the interaction of excessive smartphone use and online self-disclosure on loneliness.

However, we found no such relation for loneliness; among those who engaged in little online self-disclosure, excessive use did not increase loneliness 4 months later. An explanation might lie in the specific type of smartphone use users engage in. For example, a recent longitudinal study showed that heavy communicative Facebook use increased loneliness. ${ }^{31}$ Therefore, future research on the different types of excessive smartphone use (i.e., communicative vs. noncommunicative) could shed further light on the relations between excessive use, online self-disclosure, loneliness, and stress. In addition, it also seems relevant to differentiate between public disclosure, which is visible to a large group of individuals (e.g., on SNSs) and private disclosure (e.g., calling, private messages), which is typically targeted at selected individuals. ${ }^{59}$

On the other hand, we could show that if individuals use their phone for self-disclosure, excessive smartphone use actually helped them relieve stress and loneliness. Previous research suggested that venting negative thoughts and feelings online comes with feelings of relief and liberation. ${ }^{38,60}$ Selfdisclosure is also a relevant predictor of relational closeness, and disclosing online can lead to rewarding experiences such as encouragement by other users. ${ }^{29}$ This experienced emotional support might lead to a feeling of being socially integrated and reduce loneliness.

The differentiation of smartphone usage types can be connected to the dimensions of functional aspects of mobile phones, that is, pragmatic and symbolic use. ${ }^{61}$ While pragmatic functional use refers to the purpose of mobile phones, symbolic functional use can be described as the effects that mobile phones have on individual's identity. In this context, using smartphones for online self-disclosure fits both types, as the purpose of communicating (i.e., the pragmatic aspect) and revealing information about oneself online (i.e., the symbolic aspect) have an impact on individuals, both on the psychological and social dimensions.
It is important to note that our findings demonstrate two separate processes of self-disclosure-namely, reducing stress and loneliness. The results remain the same even when controlling for stress (T1) in our analysis with loneliness as the dependent variable and vice versa.

Finally, it should be noted that our study represents the first longitudinal study on this topic. Since most research has been conducted with adolescents and students using a crosssectional survey design, our quota sample of smartphone users and our analysis, including controls for autoregressive effects, further account for the robustness of our results.

Yet, our study is not without limitations. First, we relied on self-report, which is common in this field of research. Regarding the assessment of psychological traits and states, researchers argue that behavioral intentions can be a valid estimate of actual behavior. ${ }^{62}$ Additionally, we were interested in the perception of excessive smartphone use, which can vary considerably between individuals and is not necessarily tied to one's objective usage. Nevertheless, we suggest that future research takes both, self-reported data and objective available data (e.g., from monitoring apps), into account to assess excessive smartphone use and its consequences. ${ }^{63,64}$

Second, although our measure for excessive smartphone use showed high internal consistency, we used items from two different scales. Although these scales are validated and well established, further validation of our scale is necessary. Third, our online self-disclosure scale was predominantly used in the Dutch context. In our case, the scale showed high reliability, but future studies should further validate this scale among other populations.

Fourth, although we focused on online behavior, there is no doubt that offline disclosure patterns and various personality traits might influence online self-disclosure. ${ }^{65}$ Therefore, we recommend to focus on offline disclosure patterns as well as personality traits such as extraversion and openness in upcoming studies. ${ }^{54}$ Future research on excessive use should also investigate the motives to engage in selfdisclosure as well as the anticipated disclosure goals, which might moderate the effects on stress and loneliness. ${ }^{59}$ For instance, previous findings suggest that the experience of stress in response to SNS use crucially depends on the reasons for sharing and not sharing private information online. ${ }^{40}$ Moreover, examining potential underlying mechanisms of the relationship of excessive smartphone use on loneliness such as emotional support is an important avenue for future research.

\section{Conclusion}

In summary, despite the raised concerns of excessive smartphone use, we could show that some usage types can have positive consequences. More specifically, we found that engaging in online self-disclosure is an important moderator in explaining this relationship. This finding provides further support that individual predispositions and motivations should be in the focus of this line of research.

\section{Acknowledgment}

The work of Kathrin Karsay was supported by the Sparkling Science Programme of the Austrian Federal Ministry of Education, Science, and Research (SPA 06/109) and the Research Foundation - Flanders. 


\section{Author Disclosure Statement}

No competing financial interests exist.

\section{Funding Information}

No funding was received for this article.

\section{References}

1. Thomée S. Mobile phone use and mental health. A review of the research that takes a psychological perspective on exposure. International Journal of Environmental Research and Public Health 2018; 15:2692.

2. Barnes SJ, Pressey AD, Scornavacca E. Mobile ubiquity: understanding the relationship between cognitive absorption, smartphone addiction and social network services. Computers in Human Behavior 2019; 90:246-258.

3. Vorderer P, Krämer N, Schneider FM. Permanently online permanently connected: explorations into university students' use of social media and mobile smart devices. Computers in Human Behavior 2016; 63:694-703.

4. Hefner D, Knop K, Schmitt S, et al. Rules? Role model? Relationship? The impact of parents on their children's problematic mobile phone involvement. Media Psychology 2019; 22:82-108.

5. Valkenburg PM, Peter J. The differential susceptibility to media effects model. Journal of Communication 2013; 63:221-243.

6. Ko H-C, Kuo F-Y. Can blogging enhance subjective wellbeing through self-disclosure? CyberPsychology and Behavior 2009 ; $12: 75-79$.

7. Chen HT, Li X. The contribution of mobile social media to social capital and psychological well-being: examining the role of communicative use, friending and self-disclosure. Computers in Human Behavior 2017; 75:958-965.

8. Huang HY. Examining the beneficial effects of individual's self-disclosure on the social network site. Computers in Human Behavior 2016; 57:122-132.

9. Beranuy M, Oberst U, Carbonell X, et al. Problematic internet and mobile phone use and clinical symptoms in college students: the role of emotional intelligence. Computers in Human Behavior 2009; 25:1182-1187.

10. Bian M, Leung L. Linking loneliness, shyness, smartphone addiction symptoms, and patterns of smartphone use to social capital. Social Science Computer Review 2015; 33:61-79.

11. Bianchi A, Phillips JG. Psychological predictors of problem mobile phone use. CyberPsychology and Behavior 2005; 8: 39-51.

12. Darcin AE, Kose S, Noyan CO, et al. Smartphone addiction and its relationship with social anxiety and loneliness. Behaviour and Information Technology 2016; 35:520-525.

13. Hawi NS, Samaha M. To excel or not to excel: strong evidence on the adverse effect of smartphone addiction on academic performance. Computers and Education 2016; 98:81-89.

14. Cho HY, Kim DJ, Park JW. Stress and adult smartphone addiction: mediation by self-control, neuroticism, and extraversion. Stress Health 2017; 33:624-630.

15. Lee YK, Chang CT, Lin Y, et al. The dark side of smartphone usage: psychological traits, compulsive behavior and technostress. Computers in Human Behavior 2014; 31:373-383.

16. Herrero J, Urueña A, Torres A, et al. Smartphone addiction: psychosocial correlates, risky attitudes, and smartphone harm. Journal of Risk Research 2017; 9877:1-12.

17. Pew Research Center (2019). Smartphone ownership is growing rapidly around the world, but not always equally. https:// www.pewresearch.org/global/2019/02/05/smartphone-owner ship-is-growing-rapidly-around-the-world-but-not-alwaysequally/ (accessed September 17, 2019).

18. Pew Research Center (2018). Social Media use in 2018. https://www.pewinternet.org/2018/03/01/social-media-usein-2018/ (accessed September 17, 2019).

19. Kardefelt-Winther D. A conceptual and methodological critique of internet addiction research: towards a model of compensatory internet use. Computers in Human Behavior 2014; 31:351-354.

20. Kwon M, Lee J-Y, Won W-Y, et al. Development and validation of a Smartphone Addiction Scale (SAS). PLoS One 2013; 8:e56936.

21. Andalibi N, Ozturk P, Forte A. (2017) Sensitive selfdisclosures, responses, and social support on Instagram: the case of \#depression. In: Proceedings of the 2017 ACM Conference on Computer Supported Cooperative Work and Social Computing. New York: ACM, pp. 1485-1500.

22. Chiu S. The relationship between life stress and smartphone addiction on Taiwanese university student: a mediation model of learning self-efficacy and social self-efficacy. Computers in Human Behavior 2014; 34:49-57.

23. Deursen AJAM Van, Bolle CL, Hegner SM, et al. Modeling habitual and addictive smartphone behavior: the role of smartphone usage types, emotional intelligence, social stress, self-regulation, age, and gender. Computers in Human Behavior 2015; 45:411-420.

24. Haug S, Castro RPAZ, Kwon MIN, et al. Smartphone use and smartphone addiction among young people in Switzerland. Journal of Behavioral Addictions 2015; 4:299-307.

25. Jeong SH, Kim HJ, Yum JY, et al. What type of content are smartphone users addicted to? SNS vs. games. Computers in Human Behavior 2016; 54:10-17.

26. Thomée S, Härenstam A, Hagberg M. Mobile phone use and stress, sleep disturbances, and symptoms of depression among young adults-a prospective cohort study. BMC Public Health 2011; 11:1-11.

27. Wang J, Wang H, Gaskin J, et al. The role of stress and motivation in problematic smartphone use among college students. Computers in Human Behavior 2015; 53:181-188.

28. Kraut R, Patterson M, Lundmark V, et al. A social technology that reduces social investment and psychological well-being? American Psychologist 1998; 53:1011-1031.

29. Valkenburg PM, Peter J. Online communication and adolescent well-being: testing the stimulation versus the displacement hypothesis. Journal of Computer-Mediated Communication 2007; 12:1169-1182.

30. Chotpitayasunondh V, Douglas KM. How "phubbing", becomes the norm: the antecedents and consequences of snubbing via smartphone. Computers in Human Behavior 2016; 52:591-600.

31. Mahapatra S. Smartphone addiction and associated consequences: role of loneliness and self-regulation. Behaviour and Information Technology 2019; 00:1-12.

32. Güzeller CO, Cosguner T. Development of a problematic mobile phone use scale for Turkish adolescents. Cyberpsychology Behavior and Social Networking 2012; 15:205-211.

33. Kim JH. Psychological issues and problematic use of smartphone: ADHD's moderating role in the associations among loneliness, need for social assurance, need for immediate connection, and problematic use of smartphone. Computers in Human Behavior 2018; 80:390-398.

34. Kim J-H. Longitudinal associations among psychological issues and problematic use of smartphones. Journal of Media Psychology 2017:1-11. 
35. Wang K, Frison E, Eggermont $\mathrm{S}$, et al. Active public Facebook use and adolescents' feelings of loneliness: evidence for a curvilinear relationship. Journal of Adolescence 2018; 67:35-44.

36. Brunell AB. (2007) Self-disclosure. In: Baumeister RF, Vohs KD, eds. Encyclopedia of Social Psychology. Thousand Oaks: SAGE Publications, Inc., pp. 811-812.

37. Kim J, Dindia K. (2011) Online self-disclosure: a review of research. In: Wright KB, Webb LM, eds. Computer-Mediated Communication in Personal Relationships. New York: Peter Lang, pp. 156-180.

38. Zhang R. The stress-buffering effect of self-disclosure on Facebook: an examination of stressful life events, social support, and mental health among college students. Computers in Human Behavior 2017; 75:527-537.

39. Frison E, Eggermont S. The impact of daily stress on adolescents' depressed mood: the role of social support seeking through Facebook. Computers in Human Behavior 2015; 44:315-325.

40. Bevan JL, Gomez R, Sparks L. Disclosures about important life events on Facebook: relationships with stress and quality of life. Computers in Human Behavior 2014; 39:246-253.

41. Shaw LH, Gant LM. In defense of the Internet: the relationship between Internet communication and depression, loneliness, self-esteem, and perceived social support. CyberPsychology and Behavior 2002; 5:157-171.

42. Clark JL, Algoe SB, Green MC. Social network sites and well-being: the role of social connection. Current Directions in Psychological Science 2018; 27:32-37.

43. große Deters F, Mehl MR. Does posting Facebook status updates increase or decrease loneliness? An online social networking experiment. Social Psychological and Personality Science 2013; 4:579-586.

44. Apaolaza V, Hartmann P, Medina E, et al. The relationship between socializing on the Spanish online networking site Tuenti and teenagers' subjective wellbeing: the roles of self-esteem and loneliness. Computers in Human Behavior 2013; 29:1282-1289.

45. Valkenburg PM, Peter J. The effects of instant messaging on the quality of adolescents' existing friendships: a longitudinal study. Journal of Communication 2009; 59:79-97.

46. Knop K, Hefner D, Schmitt S, et al. Mediatisierung Mobil. Handy-Und Mobile Internetnutzung von Kindern Und Jugendlichen 2015. Schriftenreihe Medienforschung der Landesanstalt für Medien NRW, Band 77. Leipzig, Germany: Vistas.

47. LaRose R, Lin CA, Eastin MS. Unregulated internet usage: addiction, habit, or deficient self-regulation? Media Psychology 2003; 5:225-253.

48. Schouten AP, Valkenburg PM, Peter J. Precursors and underlying processes of adolescents' online self-disclosure: developing and testing an "Internet-attribute-perception" model. Media Psychology 2007; 10:292-315.

49. Lehman KA, Burns MN, Gagen EC, et al. Development of the brief inventory of perceived stress. Journal of Clinical Psychology 2012; 68:631-644.

50. Russell DW. UCLA Loneliness scale (version 3): reliability, validity, and factor structure. Journal of Personality Assessment 1996; 66:20-40.

51. Rosseel Y. lavaan: an $\mathrm{R}$ package for structural equation modeling. Journal of Statistical Software 2012; 48:1-36.

52. Hayes AF, Matthes J. Computational procedures for probing interactions in OLS and logistic regression: SPSS and
SAS implementations. Behavior Research Methods 2009; 41:924-936.

53. Kim J, LaRose R, Peng W. Loneliness as the cause and the effect of problematic Internet use: the relationship between Internet use and psychological well-being. CyberPsychology and Behavior 2009; 12:451-455.

54. van der Aa N, Overbeeck G, Engels RCME, et al. Daily and compulsive internet use and well-being in adolescence: a diathesis-stress model based on big five personality traits. Journal of Youth and Adolescence 2009; 38:765-776.

55. Elhai JD, Dvorak RD, Levine JC, et al. Problematic smartphone use: a conceptual overview and systematic review of relations with anxiety and depression psychopathology. Journal of Affective Disorders 2017; 207: 251-259.

56. Elhai JD, Levine JC, Dvorak RD, Hall BJ. Non-social features of smartphone use are most related to depression, anxiety and problematic smartphone use. Computers in Human Behavior 2017; 69:75-82.

57. Wang JL, Gaskin J, Rost DH, et al. The reciprocal relationship between passive social networking site (SNS) usage and users' subjective well-being. Social Science Computer Review 2018; 36:511-522.

58. Schmuck D, Karsay K, Matthes J, Stevic A. "Looking up and feeling down." The influence of mobile social networking site use on upward social comparison, self-esteem, and well-being of adult smartphone users. Telematics and Informatics 2019; 42:101240.

59. Bazarova NN, Choi YH. Self-disclosure in social media: extending the functional approach to disclosure motivations and characteristics on social network sites. Journal of Communication 2014; 64:635-657.

60. Wendorf JE, Yang F. Benefits of a negative post: effects of computer-mediated venting on relationship maintenance. Computers in Human Behavior 2015; 52:271-277.

61. Wirth W, Von Pape T, et al. An integrative model of mobile phone appropriation. Journal of Computer-Mediated Communication 2008; 13:593-617.

62. Webb TL, Sheeran P. Does changing behavioral intentions engender behavior change? A meta-analysis of the experimental evidence. Psychological Bulletin 2006; 132:249-268.

63. Scharkow M. The reliability and temporal stability of selfreported media exposure: a meta-analysis. Communication Methods and Measures 2019; 13:198-211.

64. Naab TK, Karnowski, V, Schlütz D. Reporting mobile social media use: how survey and experience sampling measures differ. Communication Methods and Measures 2019; 13:126-147.

65. Forest AL, Wood J V. When social networking is not working: individuals with low self-esteem recognize but do not reap the benefits of self-disclosure on Facebook. Psychological Science 2012; 23:295-302.

Address correspondence to: Dr. Kathrin Karsay Department of Communication University of Vienna Währinger strasse 29 Vienna 1090 Austria

E-mail: kathrin.karsay@univie.ac.at 


\section{Appendix}

\section{Excessive Smartphone Use}

Five-point scale from 1 ("completely disagree") to 5 ("completely agree"): (1) "If I see the smartphone lying somewhere or I receive a message, then I just have to look at it-there is no other way", (2) "Even when I am busy with something else, I often look at my mobile phone or check messages", (3) "I often think of my mobile phone when I am doing something else", (4) "I notice that I do not have my smartphone use under control", (5) "I use the phone so often that it interferes with other activities", (6) "I would miss the phone if I did not have it anymore", (7) "I often spend more time with the phone than I originally intended".

\section{Online Self-Disclosure}

Five-point scale ranging from 1 ("never") to 5 ("always"): "When you use social media platforms on your mobile phone, how often do you normally communicate...", (1) "...your personal feelings"; (2) "...your worries and fears"; (3) "...your private problems"?

\section{Stress}

Six-point scale from 1 ("never") to 6 ("several times a day"): "During the last week how often..." (1) “...did you feel as if difficulties were so great that you could not overcome them?", (2) “... did you have too many things to do?", (3) "... did you feel like you were in a hurry?", (4) " ... did you find yourself in conflict situations?", (5) “... did you feel like you had to do things when you didn't want to do them at all?", (6) "... did you feel criticized or condemned?", (7) “... did you feel as if difficulties were so great that you couldn't overcome them?", (8) "... did you have too many worries?"

\section{Loneliness}

Five-point scale from 1 ("completely disagree") to 5 ("completely agree"): (1) "I often feel alone", (2) "I often think I'm not close to anyone anymore", (3) "Sometimes I think that nobody really knows me", (4) "I often feel isolated from others". 